\title{
Substance Use and Associated Factors among Retro Viral Infected (RVI) Patients on Antiretroviral Treatment (ART) at Assela Teaching Hospital
}

\section{Mesfin Tafa Segni*, Getu Teshome and Hailu Fekadu Demissie}

Department of Public Health, College of Health Sciences, Arsi University, Assela, Ethiopia

\begin{abstract}
Introduction: Use of substances such as alcohol, khat and tobacco has become one of the rising major public health and socio-economic problems worldwide. Many people at risk for or already infected with HIV abuse alcohol, contributing to the difficulties in preventing the spread of the infection and treating infected patients.
\end{abstract}

Objective: The objective of the study was to assess prevalence of Substance use and associated factors among Retro Viral Infected (RVI) Patients on Antiretroviral Treatment (ART) at Assela Teaching Hospital, Assela Ethiopia.

Methodology: A cross sectional study was conducted from June to August 2016 among 418 RVI patients who were on ART follow up at Assela Teaching Hospital. The participants were selected systematic random sampling. Socio demographic data and other relevant data was collected using semi structured questionnaire. The data was coded, cleaned and entered using Epi Info 3.5.3 then exported to Statistical Package for the Social science (SPSS) version 21 for further analysis. Descriptive statistics and logistic regression analysis was used.

Results: The prevalence of substance use at least once in their lifetime among RVI patient was $27.5 \%$ whereas the prevalence of current substance use was $3.8 \%$ and Alcohol was predominantly abused drug. Alcohol was the being male and friend or family substance use was strong predictors of substance abuse among the respondents.

Conclusion and recommendation: This study revealed that the prevalence of substance use among RVI patient was significant. We recommend that awareness creation about the influence of substance use on HIV by health professionals have invaluable benefit.

Keywords: Substance use; RVI patients; On ART follow up; Assela teaching hospital; Ethiopia

\section{Introduction}

Use of substances such as alcohol, khat and tobacco has become one of the rising major public health and socio-economic problems worldwide [1,2]. Substance abuse is a primary vector for the spread of HIV through engagement in a number of high-risk behaviors, either when intoxicated or engage in prostitution in order to obtain drugs [3]. Poor Antiretroviral treatment adherence is public health problem among RVI patients in developing countries, like Ethiopia [4]. It has been reported in multiple studies for decades globally that substance abuse can lead to risky sexual behaviors. These risky sexual behaviors can lead to HIV infection and, ultimately, to AIDS and early death [5]. In addition to increasing the risk of HIV transmission, substance use can affect people's overall health and make them more susceptible to HIV infection and, in those already infected with HIV, substance use can hasten disease progression and negatively affect adherence to treatment [6].

Uses of heavy alcohol has been correlated with a lifetime tendency toward high-risk sexual behaviors, including multiple sex partners, unprotected intercourse, sex with high-risk partners (e.g. injection drug users, prostitutes) and the exchange of sex for money or drugs $[7,8]$. People infected with HIV are nearly twice more likely to use alcohol than people in the general population. Moreover, up to 50 percent of adults with HIV infection have a history of alcohol problems. Alcohol can increase how fast the virus grows, leading to higher amounts of virus (i.e., the viral load) in the body. Those high concentrations, in turn, can increase the spread of the disease. Alcohol induced immunosuppression that exacerbates the HIVrelated immunosuppression, will further exacerbate progression of the disease [9]. In HIV-infected people undergoing treatment, concurrent alcohol abuse often renders treatment ineffective because patients frequently fail to adhere to the strict treatment regimens necessary to achieve control of the infection. Moreover, alcohol may interact with ART medications and exacerbate adverse effects of these medications [10].

The use of khat can be harmful that increase the risk of contracting HIV and other sexually transmitted diseases [11]. Among prostitutes in Djibouti. Chat chewer have insomnia as a problem thus to overcome this they abuses alcohol or other sedative which finally result in constitute risky behavior contributing to the spread of HIV infection [12]. High prevalence of smoking among people living with HIV/ AIDS (PLWHA) is well-documented in developed countries, ranging from $40 \%$ to $74 \%$ and approximately 2 to 3 -fold higher than that in the general population [13]. HIV-positive smokers have significantly poorer immunologic response, greater risk of virologic rebound and more frequent immunologic failure as compared to their nonsmoking counterparts [14]. People with HIV who smoke are more likely to suffer from several complications from HIV medication and long-term effects of HIV disease and concomitant treatments [15]. Despite this extensive impact of substance use in RVI patient, there is research in the study area. This study may put many important results in understanding the

*Corresponding author: Mesfin Tafa Segni, Department of Public Health, College of Health Sciences, Arsi University, Assela, Ethiopia; Tel: 2519108673899; E-mail: mesfintafa2011@gmail.com

Received March 16, 2017; Accepted June 26, 2017; Published June 30, 2017

Citation: Segni MT, Teshome G, Demissie HF (2017) Substance Use and Associated Factors among Retro Viral Infected (RVI) Patients on Antiretroviral Treatment (ART) at Assela Teaching Hospital. J AIDS Clin Res 8: 707. doi: 10.4172/2155-6113.1000707

Copyright: ( 2017 Segni MT, et al. This is an open-access article distributed under the terms of the Creative Commons Attribution License, which permits unrestricted use, distribution, and reproduction in any medium, provided the original author and source are credited. 
magnitude of substance use and determinant factor among RVI patient in Asella hospital.

\section{Methodology}

\section{Setting}

The study was conducted at Assela Teaching and Referral Hospital from June to August 2016, which is located $175 \mathrm{~km}$ from Addis Ababa in southeast. Assela Hospital was established in 1958 and currently giving services in-patient and out-patient services for 3 million population. ART service was started at hospital since 1998 and currently, in 2016 more than 3427 HIV patient are on ART and 60 are on pre ART initiation.

\section{Study design}

Institutional based cross-sectional study design was used

\section{Population}

Source of population: All RVI patients who are currently on ART follow up.

Study population: Those ART patients who were randomly selected from the sampling frame of ART patients.

\section{Inclusion and exclusion criteria}

Inclusion criteria: RVI patients who had follow up in Asella referral and teaching hospital who were willing to participate in the study during the time of data collection were included.

Exclusive criteria: Children and non-respondents.

\section{Sample size and sampling technique}

The sample size was calculated by using single population proportion formula, taking $95 \%$ CI, $5 \%$ degree of precisions and $55 \%$ of proportion of alcohol taking among PLWHA from a study in Vietnam and adding 10\% of non-response rate a total of 418 study participants included in the study. Systematic random sampling technique was applied to select individuals. First k value was determined from total population (3427) and sample size (418). Then, sample was taken every $\mathrm{k}$ value from sampling frame [6].

\section{Operational definitions}

Substance use: For this study it is defined as drinking alcohol, chewing khat, smoking cigarettes and illicit drugs.

\section{Data collection methods and quality assurance}

Data was collected by semi structured self-administered questionnaire prepared in English and translated to Amharic and retranslated to English to ensure its consistency. The questionnaires were adopted and modified from WHO-substance use survey questionnaire. It consists of sociodemographic variables, substance use and health status related questions. Participation was on voluntary basis and confidentiality was maintained to encourage accurate and honest self-disclosure. For some specific question secondary data (card of the patient) was reviewed. Supervision was done while data collectors collect data and the information was checked for completeness and internal consistency.

\section{Data analysis}

The data was coded and entered in to computer using Epi-info 3.5.4 and then transferred to Statistical Package for Social Science (SPSS) version 21 software programs for further analysis. Descriptive statistics was used to describe frequency and percentage. Bivariate and multivariate analysis was employed to identify factors associated with the outcome variable.

\section{Ethical considerations}

Before the start of the data collection process ethical clearance was secured from Research and Ethics Committee of college of Health Sciences, Arsi University. Data was collected after participants were informed about the objectives of the study.

\section{Results}

\section{Socio-demographic characteristics}

A total of 418 participants were included in the study with $100 \%$ response rate. Majority of the respondents were between 36-45years (37.1\%). More than half of study participants were female 229 (54.8\%). Ethnically Oromo (65.3\%) and Amhara (32.1\%) account the majority of the participant. Regarding the religion most of them were Orthodox 260 (62.2\%) followed by Muslim 94 (22.5\%). About $45 \%$ of the respondent completed primary school. Those who live in urban area constitute the majority of participant (69.1\%). And about $40.9 \%$ of them had total income 501-1000 birr per month followed by those who earn $<=500$ birr (22.7\%) (Table 1).

\begin{tabular}{|c|c|c|c|}
\hline Characteristics & & Frequency & Percentage \\
\hline \multirow[t]{2}{*}{ Sex } & Male & 189 & 45.2 \\
\hline & Female & 229 & 54.8 \\
\hline \multirow[t]{5}{*}{ Age } & $<25$ & 34 & 8.1 \\
\hline & $26-35$ & 132 & 31.6 \\
\hline & $36-45$ & 155 & 37.1 \\
\hline & $46-55$ & 68 & 16.3 \\
\hline & $>55$ & 29 & 6.9 \\
\hline \multirow[t]{4}{*}{ Religion } & Orthodox & 260 & 62.2 \\
\hline & Muslim & 94 & 22.5 \\
\hline & Protestant & 59 & 14.1 \\
\hline & Other & 5 & 1.2 \\
\hline \multirow[t]{4}{*}{ Educational } & College and above & 45 & 10.8 \\
\hline & Illiterate & 74 & 17.7 \\
\hline & Primary school & 189 & 45.2 \\
\hline & Secondary school & 110 & 26.3 \\
\hline \multirow[t]{4}{*}{ Marital status } & Divorced & 59 & 14.1 \\
\hline & Married & 241 & 57.7 \\
\hline & Single & 60 & 14.4 \\
\hline & Widowed & 58 & 13.9 \\
\hline \multirow[t]{7}{*}{ Occupation } & Farmer & 78 & 18.7 \\
\hline & Merchants & 82 & 19.6 \\
\hline & Housewife & 112 & 26.8 \\
\hline & Driver & 19 & 4.5 \\
\hline & Employed & 77 & 18.4 \\
\hline & Students & 16 & 3.8 \\
\hline & Other & 34 & 8.1 \\
\hline \multirow[t]{2}{*}{ Address } & Rural & 129 & 30.9 \\
\hline & Urban & 289 & 69.1 \\
\hline \multirow[t]{5}{*}{ Income } & $=<500$ & 95 & 22.7 \\
\hline & $501-1000$ & 171 & 40.9 \\
\hline & $1001-1500$ & 66 & 15.8 \\
\hline & $1501-2000$ & 44 & 10.5 \\
\hline & $>2000$ & 42 & 10.0 \\
\hline
\end{tabular}

Table 1: Socio-demographic characteristics of RVI patient at Assela Hospital Assela Ethiopia, 2016. 


\section{Magnitude substance use}

Among the study participants, 115 (27.5\%) have a history of substance abuse. The prevalence of current Alcohol, Alcohol and cigarettes and Alcohol and khat was $13.6 \%, 4.8 \%$ and $4.1 \%$, respectively. Those who consumed all alcohol, cigarettes and khat and those who consume only khat account $2.2 \%$. Majority of participant who has used substance previously stop after they start ART. Moreover, the prevalence of substance use currently in the last 30 days among PLWHA were $3.8 \%$, of which alcohol and cigarettes smoking account $2.6 \%$ and $1.2 \%$, respectively (Table 2 ).

\section{Factors to initiate substance use}

The most common attributed factor that initiated them to start substance use were to get personal pleasure $(29.6 \%)$, to be sociable (28.7\%) and peer influence (27\%). About $83.5 \%$ of the consumer had bad attitude towards their behavior of substance use. Out of the total participants $45.7 \%$ of them had friends who consume substance where as $24.4 \%$ of them had family member who uses substance (Table 3 ).

\section{Substance use and patients clinical background}

Most of the participants were diagnosed to be seropositive in between 2001-2005 years E.C. About $90 \%$ of the respondents were clinical stage I RVI patients and 32.5\% had CD4 count 351-500 while $3.1 \%$ of them have CD4 count of less than 200. Concerning their adherence to medication, $83 \%$ of them did not discontinue and take their drugs regularly. But 70 (17\%) of the respondent were not adherent to the drugs (Table 4).

\section{Bivariate and multivariate logistic regression}

Initially socio-demographic variable, friend use of substance, family use of substance and WHO stages of HIV were considered in the bivariate analysis. In bivariate analysis sex, educational level, marital status, occupation, friend substance use and family substance use were significant associated with substance use. Being male was 17.63 times $(\mathrm{COR}=17.63$; 95\% $\mathrm{CI}=9.56,32.50)$ more likely to use substance than their counterpart. Individuals who were illiterate 0.42 times $(\mathrm{COR}=0.42 ; 95 \% \mathrm{CI}=0.18,0.98)$ less likely to use substance than

\begin{tabular}{|l|c|c|}
\hline Substance use once in life & Frequency & Percentage \\
\hline Yes & 115 & 27.5 \\
\hline No & 303 & 72.5 \\
\hline Types of substance used & & \\
\hline Alcohol & 57 & 13.6 \\
\hline Alcohol and khat & 17 & 4.1 \\
\hline Alcohol and cigarettes & 20 & 4.8 \\
\hline All & 9 & 2.2 \\
\hline Cigarette & 3 & 0.7 \\
\hline Khat & 9 & 2.2 \\
\hline Substance use in the past 30 days & & 3.8 \\
\hline Yes & 16 & 96.2 \\
\hline No & 402 & 2.6 \\
\hline Current substance use & & 1.2 \\
\hline Alcohol & 11 & \\
\hline Cigarettes & 4 & 20.9 \\
\hline Discontinue substance after diagnosis & & \\
\hline Yes & 91 & \\
\hline No & 24 & \\
\hline
\end{tabular}

Table 2: Magnitude and types of substance use among RVI patient in Asella hospital, August 2016.

\begin{tabular}{|l|c|c|}
\hline Reason to start substance use & Frequency & Percentage \\
\hline Availability of substance & 5 & 4.3 \\
\hline Peer influence & 31 & 27 \\
\hline Religious practice & 3 & 2.6 \\
\hline To be sociable & 33 & 28.7 \\
\hline To get personal pleasure & 34 & 29.6 \\
\hline To increase pleasure during sex & 4 & 3.5 \\
\hline To relief from tension & 3 & 2.6 \\
\hline To stay awake & 2 & 1.7 \\
\hline Attitude towards sub use & & 83.5 \\
\hline Bad & 96 & 16.5 \\
\hline Good & 19 & \\
\hline Having friends with sub use & & 45.7 \\
\hline Yes & 191 & 54.3 \\
\hline No & 227 & \\
\hline Family use of substance & & 24.4 \\
\hline Yes & 102 & 75.6 \\
\hline No & 316 & \\
\hline
\end{tabular}

Table 3: Factors that initiate RVI patient to use substance in Asella Hospital, August 2016.

\begin{tabular}{|c|c|c|}
\hline Year of diagnosis(E.C) & Frequency & Percentage \\
\hline 1990-1995 & 14 & 3.3 \\
\hline 1996-2000 & 142 & 34.0 \\
\hline 2001-2005 & 198 & 47.4 \\
\hline$>2005$ & 64 & 15.3 \\
\hline \multicolumn{3}{|l|}{ Clinical stage } \\
\hline Stage I & 375 & 89.7 \\
\hline Stage II & 30 & 7.2 \\
\hline Stage III & 13 & 3.1 \\
\hline \multicolumn{3}{|l|}{ Current CD4 count } \\
\hline$<200$ & 13 & 3.1 \\
\hline 201-350 & 113 & 27.0 \\
\hline $351-500$ & 136 & 32.5 \\
\hline $501-650$ & 110 & 26.3 \\
\hline$>650$ & 46 & 11.0 \\
\hline \multicolumn{3}{|l|}{ Currently on ART } \\
\hline Yes & 411 & 98.3 \\
\hline No & 7 & 1.7 \\
\hline \multicolumn{3}{|c|}{ Have you ever discontinue ART } \\
\hline Yes & 70 & 17 \\
\hline No & 341 & 83 \\
\hline \multicolumn{3}{|l|}{ Dose missed/month } \\
\hline$<=3$ dose missed & 41 & 58.6 \\
\hline 4-8 dose missed & 13 & 18.5 \\
\hline$>=9$ dose missed & 16 & 22.9 \\
\hline
\end{tabular}

Table 4: Clinical background and ART adherence of the participants, of Assela Hospital in 2016.

educated person. Being single were 6.4 times $(\mathrm{COR}=6.4 ; 95 \% \mathrm{CI}=2.49$, 16.30) more risk for substance use among RVI patient. Driver were 4.53 times $\mathrm{COR}=4.53 ; 95 \% \mathrm{CI}=1.36,15.12)$ to consume substance. Those whose friend use substance were 0.98 times $(\mathrm{COR}=0.98 ; 95 \% \mathrm{CI}=0.06$, $0.17)$ less likely to use substance use and relative to those whose family did not use substance, those whose family uses substance were 4 times $(\mathrm{COR}=4.06 ; 95 \% \mathrm{CI}=2.08,7.92)$ more likely to use substance. These variables were taken and analyzed together using multivariate logistic regression model. 
Page 4 of 5

\begin{tabular}{|c|c|c|c|c|}
\hline \multirow[t]{2}{*}{ Variable } & \multicolumn{2}{|c|}{ Substance use } & \multicolumn{2}{|c|}{ Odds Ratio } \\
\hline & No & Yes & COR $95 \% \mathrm{Cl}$ & AOR $95 \% \mathrm{Cl}$ \\
\hline \multicolumn{5}{|l|}{ Sex } \\
\hline Male & $88(46.6)$ & $101(53.4)$ & $17.63(9.56,32.50)^{\star *}$ & $14.1(5.84,33.87)^{\star \star}$ \\
\hline Female & $215(93.9)$ & $14(6.1)$ & 1 & 1 \\
\hline \multicolumn{5}{|l|}{ Educational status } \\
\hline Illiterate & $60(81.1)$ & $14(18.9)$ & $0.42(0.18,0.98)^{\star}$ & $0.87(0.22,3.43)$ \\
\hline Primary & $134(70.9)$ & $55(29.1)$ & $0.74(0.37,1.48)$ & $0.79(0.25,2.50)$ \\
\hline Secondary & $80(72.7)$ & $30(27.3)$ & $0.68(0.32,1.43)$ & $0.70(0.21,2.29)$ \\
\hline College and above & $29(64.4)$ & $16(35.6)$ & 1 & 1 \\
\hline \multicolumn{5}{|l|}{ Marital status } \\
\hline Divorced & $48(81.4)$ & $11(18.6)$ & $1.67(0.60,4.66)$ & $1.01(0.27,3.78)$ \\
\hline Married & $172(71.4)$ & $69(28.6)$ & $2.88(1.25,6.66)^{\star}$ & $1.06(0.35,3.23)$ \\
\hline Single & $32(53.3)$ & $28(46.7)$ & $6.4(2.49,16.30)^{\star \star}$ & $3.54(0.92,13.57)$ \\
\hline Widowed & $51(87.9)$ & $7(12.1)$ & 1 & 1 \\
\hline \multicolumn{5}{|l|}{ Occupation } \\
\hline Housewife & $102(91.1)$ & $10(8.9)$ & $0.21(0.08,0.54)^{* *}$ & $1.02(0.26,3.98)$ \\
\hline Employed & $51(66.2)$ & $26(33.8)$ & $1.07(0.45,2.52)$ & $1.07(0.30,3.79)$ \\
\hline Merchant & $56(68.3)$ & $26(31.7)$ & $0.97(0.41,2.29)$ & $1.35(0.43,4.19)$ \\
\hline Farmer & $52(66.7)$ & $26(33.3)$ & $1.05(0.44,2.47)$ & $1.31(0.42,4.05)$ \\
\hline Driver & $6(31.6)$ & $13(68.4)$ & $4.53(1.36,15.12)^{\star}$ & $1.54(0.31,7.51)$ \\
\hline Students & $13(81.2)$ & $3(18.8)$ & $0.48(0.11,2.05)$ & $0.55(0.62,4.92)$ \\
\hline Others & $23(67.6)$ & $11(32.4)$ & 1 & 1 \\
\hline \multicolumn{5}{|c|}{ Friends substance use } \\
\hline Yes & $96(50.3)$ & $95(49.7)$ & $0.98(0.06,0.17)^{\star *}$ & $0.11(0.06,0.22)^{\star *}$ \\
\hline No & $207(91.2)$ & $20(8.8)$ & 1 & 1 \\
\hline \multicolumn{5}{|c|}{ Family substance use } \\
\hline Yes & $91(89.2)$ & $11(10.8)$ & $4(2.08,7.92)^{\star *}$ & $2.66(1.15,6.13)^{*}$ \\
\hline No & $212(67.1)$ & $104(32.9)$ & 1 & \\
\hline
\end{tabular}

NB: ${ }^{*} P$ value $<0.05,{ }^{* *} P$ value $<0.001$

Table 5: Substance use and its associated factor among RVI patient in Asella hospital, August 2016.

After controlling for the effects of potentially confounding factors using multivariate logistic regression model sex, family substance use and friend substance use were found to be statistically significant predictors of substance use. Being male is strongly associated with substance use (AOR: 14.1(5.84, 33.87)). Relative to those whose friends do not use substance, those whose friends use substance were 0.11 times less likely to use substance (AOR: $0.11(0.06,0.22)$. Those whose families use substance were 2.66 times more likely associated with substance use (AOR: $2.66(1.15,6.13)$ as compared to those whose families not (Table 5).

\section{Discussion}

In this study the overall prevalence of substance use at least once in life among the respondents was $27.5 \%$.This is significantly higher than the prevalence of lifetime substance use in a study done in Myanma (7.9\%) [16]. Worthwhile, the study found that about $3.8 \%$ of the participants were still using substance. This signifies that most HIV infected individual had stopped substance use. The underlying reasons for lower prevalence of current substance use by HIV-infected individuals may be related to their awareness of being sick, and the necessity to adhere to healthier life style recommendations to control their disease. They also may be concerned about the consequences of alcohol on the effect of antiretroviral drugs.

The prevalence of former and current alcoholic drinker is $13.6 \%$ and $2.6 \%$, respectively. This is lower than similar study done in Vietnam (55\%) and Brown University (48\%) $[17,18]$. Studies in Southern Brazil reveals that current alcohol consumption in RVI patient was $66.6 \%$ which is by far higher than result of this study [19].

The prevalence of former smoker among HIV positive patient were $21.7 \%$ in South Africa, $64.3 \%$ in India, $20.3 \%$ in Uruguay and $9.5 \%$ in Vietnam $[18,20,21]$. However, it was lower in this study which is $0.7 \%$. The prevalence of current smoker is $1.2 \%$ which is not significant compared to similar studies done in South Africa (15\%), in Vietnam (36.1\%), in Birmingham University (39\%), Uruguay (42.4\%) and China (62\%) [18,22-24]. Thus the prevalence of current smoking among HIV infected person is considerably higher worldwide due to urbanization, civilization and higher educational level. There were greater proportion of female in this study which may attributed to low smoking prevalence, black female being much less likely to smoke [25].

In this particular study the life time prevalence of Khat chewing was $2.2 \%$ which is lower than study in Jimma University (23.0\%) and in Gore town in Oromia region (61\%) [26,27]. This may result from location difference where Khat chewing is accustomed in the society due to availability of substance.

Individual who use more than one substance is more common, for example about $40 \%$ of PLWHA were using more than one types of substance in Mayanma [16]. Crossectional study in HIV infected patient showed that heavy alcoholic drinker was more likely to smoke [28]. Cigarette smoking was independently associated with heavy alcohol consumption among HIV infected individuals [19].

This research also found that concomitant use of alcohol and Khat, 
alcohol and smoking were higher than smoking or khat chewing alone. The prevalence of both alcohol and khat user among RVI patient in this study is $4.1 \%$ which is much lower than similar study in Gore town in Oromia region (67\%) [27].

The study found out that being male is strongly associated with substance use compared to female (AOR: $14.1(5.84,33.87) \mathrm{p}=0.001$. Relative to those whose friends do not use substance, those whose friends use substance were less likely associated with substance use (AOR: $0.11(0.06,0.22) \mathrm{p}=0.001$. This is not consistent with study finding in Alabama University [24]. Degree of drug adherence, CD4 count and WHO staging is not associated with substance use which is not consistent with the study finding in Jimma [26]. Study finding in USA found that older age, low educational level, low income, homelessness, depression and high viral load were positively associated with smoking [29]. However, this association was not consistent in this study.

The prevalence of substance use in this study was higher in male that is about $53.4 \%$ of male participant. This is consistent with study finding in Jimma, Zambia and Vietnam which shows male predominance in Khat, Alcohol and Cigarettes smoking $[18,26,30]$. This could be due to due to social and biological factors or gender difference.

In this study about $67.8 \%$ of those who consume substance were engaged in risky sexual activities or did not use condom after substance use. The main reason attributed to this was intoxication with substance. This is consistent with similar study done in Myanma and Brown University [16,17].

As a conclusion, this study revealed that the life time prevalence of substance use among RVI patients was $27.2 \%$. This study also showed that substance use was strongly associated with male sex and family use of substance but less likely associated with friend substance use. One of the limitation of this study may be, the participant may be subjected to recall bias and under reporting of substance use. Even though the prevalence of substance use among RVI patient is not as high as a result from similar study, it should not be ignored and it is recommended that detail awareness creation about the influence of substance use on HIV and ART adherence by health professionals have invaluable benefit.

\section{Acknowledgement}

Our deepest gratitude goes to study subjects for their cooperation's and data collectors for their time and Arsi University, College of Health Science for material support.

\section{References}

1. Volkow ND, Li TK (2005) Drugs and alcohol: Treating and preventing abuse, addiction and their medical consequences. Pharmacol Ther 108: 3-17.

2. Kebede D, Alem A, Mitike G, Enquselassie F, Berhane F, et al. (2005) Khat and alcohol use and risky sex behaviour among in-school and out-of-school youth in Ethiopia. BMC Public Health 5: 109.

3. Centers for Disease Control and Prevention (2010) CDC

4. Asmare M, Aychiluhem M, Ayana M, Jara D (2014) Level of ART adherence and associated factors among HIV sero-positive adult on highly active antiretroviral therapy in Debre Markos Referral Hospital, Northwest Ethiopia. J Antivir Antiretrovir 6: 120-126.

5. Thomas R Syre (2012) Harar bulletin of health science. Haramaya University.

6. Centers for Disease Control and Prevention (2010) HIV in the United States: At a glance.

7. Windle M (1997) The trading of sex for money or drugs, sexually transmitted diseases (STDs), and HIV-related risk behaviors among multisubstance using alcoholic inpatients. Drug Alcohol Depend 49: 33-38

8. Avins AL, Woods WJ, Lindan CP, Hudes ES, Clark W, et al. (1994) HIV infection and risk behaviors among heterosexuals in alcohol treatment programs. JAMA 271: 515-518.
9. Samet JH, Phillips SJ, Horton NJ, Traphagen ET, Freedberg KA (2004) Detecting alcohol problems in HIV-infected patients: Use of the CAGE questionnaire. AIDS Research and Human Retroviruses 20: 151-155.

10. Bryant KJ, Nelson S, Braithwaite RS, Roach D (2010) Integrating HIV/AIDS and alcohol research, p: 33.

11. Wakgari D, Aklilu A (2011) Substance use and its predictors among undergraduate medical students of Addis Ababa University in Ethiopia. BMC Public Health 11: 660-610.

12. Abebe D, Debella A, Dejene A, Degefa A, Abebe A, et al. (2005) Khat chewing habit as a possible risk behaviour for HIV infection. Ethiop J Health Dev 19 174-181.

13. Tesoriero JM, Gieryic SM, Carrascal A, Lavigne HE (2010) Smoking among HIV positive New Yorkers: Prevalence, frequency and opportunities for cessation. AIDS Behav 14: 824-835.

14. O'Cleirigh C, Valentine SE, Pinkston M, Herman D, Bedoya CA, et al. (2014) The unique challenges facing HIV-positive patients who smoke cigarettes: HIV viremia, art adherence, engagement in HIV care and concurrent substance use. AIDS Behav 19: 178-185.

15. Shuter J, Bernstein SL, Moadel AB (2012) Cigarette smoking behaviors and beliefs in persons living with HIVIAIDS. Am J Health Behav 36: 75-85.

16. Hane KM, Areesantichai C (2014) Substance use and HIV knowledge among PLWHA in ratana metta organization Yangon, Myanmar. J Health Sci 28.

17. Stein M, Herman DS, Trisvan E, Pirraglia P, Engle P, et al. (2005) Alcohol use and sexual risk behavior among human immunodeficiency virus-positive persons. Alcoholism: Clinical and Experimental Research 29: 837-843.

18. Nguyen NPT, Tran BX, Hwang LY (2015) Prevalence of cigarette smoking and associated factors in a large sample of HIV-positive patients receiving antiretroviral therapy in Vietnam. PLoS ONE 10

19. Ikeda MLR, Barcellos NT, Alencastro PR, Wolff FH, Moreira LB, et al. (2016) Alcohol drinking pattern: A comparison between HIV infected patients and individuals from the general population. PLoS ONE 11: e0158535.

20. Leelavathy B, Narasimhamurthy B, Shetty I (2012) Prevalence of smoking and health consequences of tobacco use in HIV-positive clients in Karnataka State. International Journal of Engineering and Innovative Technology 2: 67-73.

21. Mdodo R, Frazier EL, Dube SR, Mattson CL, Sutton MY, et al. (2015) Cigarette smoking prevalence among adults with HIV compared with the general adult population in the United States: Cross-sectional surveys. Ann Intern Med 162 335-344.

22. Wawer R, Anderson P, Steel H, Venter WDF, Murdoch D, et al. (2013) The prevalence of smoking and the knowledge of smoking hazards and smoking cessation strategies among HIV positive patients in Johannesburg, South Africa. S Afr Med J 103: 858-860.

23. Luo X, Duan S, Duan Q, Pu Y, Yang Y, et al. (2014) Tobacco use among HIVinfected individuals in a rural community in Yunnan Province, China. Drug Alcohol Depend 134C: 144-150.

24. Zyambo CM, Willig JH, Cropsey KL, Carson AP, Wilson C, et al. (2015) Factors associated with smoking status among HIV-positive patients in routine clinical care. J AIDS Clin Res 6.

25. Seme A, Mariam DH, Worku A (2005) The association between substance abuse and HIV infection among people visiting HIV counseling and testing centers in Addis Ababa, Ethiopia Ethiop. J Health Dev 19: 116-125.

26. Soboka M, Tesfaye M, Feyisa GT, Hanlon C (2012) Khat use in PLWHA.

27. Waldegabrel TA, Wubetie AM (2015) Alcohol and chat use as a risk factor for HIV AIDS infection among PICT visitor I Gore town 3: 643-649

28. Gritz ER, Vidrine DJ, Lazev AB, Amick BC, Arduino RC (2004) Smoking behavior in a low-income multiethnic HIVIAIDS population. Nicotine Tob Res 6: 71-77.

29. Mamary EM, Bahrs D, Martinez S (2002) Cigarette smoking and the desire to quit among individuals living with HIV. AIDS Patient Care STDS 16: 39-42.

30. O'Connell R, Chishinga N, Kinyanda E, Patel V, Ayles H, et al. (2013) Prevalence and correlates of alcohol dependence disorder among TB and HIV infected patients in Zambia. PLoS ONE 8: e74406. 